\title{
Proposal for the Creation of a Subdiscipline: Education Informatics
}

\section{Citation}

Collins, John W., and Sharon A. Weiner. 2010. Proposal for the creation of a subdiscipline:

Education informatics. Teachers College Record 112, no. 10: 2523-2536.

\section{Published Version}

http://www.tcrecord.org/library/content.asp?contentid=15867

\section{Permanent link}

http://nrs.harvard.edu/urn-3:HUL.InstRepos:4569474

\section{Terms of Use}

This article was downloaded from Harvard University's DASH repository, and is made available under the terms and conditions applicable to Open Access Policy Articles, as set forth at http:// nrs.harvard.edu/urn-3:HUL.InstRepos:dash.current.terms-of-use\#OAP

\section{Share Your Story}

The Harvard community has made this article openly available.

Please share how this access benefits you. Submit a story.

\section{Accessibility}




\title{
Proposal for the Creation of a Subdiscipline: Education Informatics
}

\section{John Collins}

\section{Sharon Weiner}

\begin{abstract}
"Education Informatics" is the name for an emerging new sub-discipline of education. We define "Education Informatics” as the application of technology to discovering and communicating education information. This article will provide an historical and theoretical foundation for the emergence of this new sub-discipline. Existing definitions of informatics, the literature on education informatics, and the evolution of academic disciplines will be examined. The authors will explore commonalities between the two disciplines from which education informatics is derived: information science and education. They will justify the foundation of the sub-discipline, grounding it within the existing discipline of education. The article will conclude with a discussion of how this new sub-discipline might impact research and practice; a plan for incorporating the new sub-discipline in the educational system; and a proposed research agenda.
\end{abstract}

\section{Introduction}

Soon after the United States Department of Education began to contemplate the recent and extensive changes in the ERIC system, education librarians representing topranking education schools met to discuss the implications. The first meeting of the Education Research Library Forum occurred in 2005 at the Harvard University Graduate School of Education. Participants concluded that there was a need for a fresh, 
constructive approach to addressing the education information needs of researchers, teachers, students, and others. Considering the importance of information systems in the field of education, the participants agreed that a new sub-discipline of education should be promoted called "education informatics.” This new sub-discipline would incorporate new technologies and learning strategies to enhance the capture, organization, and utilization of information within the field of education. These are some of the many information challenges and problems facing the discipline of education:

- The need to collect and provide access to the gray literature in education. "Gray literature” is that which is not published in mainstream outlets such as journals. It includes: reports, white papers, syllabi and other course materials, dissertations and theses, conference proceedings and other unpublished works in a variety of media. This literature had been acquired and organized in the past by the ERIC Clearinghouses (Trester, 1981). The current lack of a central repository, however, whose charge is to acquire, provide access to, and preserve education-related gray literature, impedes access to valuable documents that do not, by definition, undergo a journal's peer review process or appear in mainstream education publications. In fact, the scope of materials encompassing gray literature has vastly expanded in relation to technology. It now can be thought to include: blogs, wikis, websites, and unindexed textual material discoverable in large scale, full-text digital collections.

- The application of education research to practice. There is a gap between research findings and the evidence-based application needs of practitioners in education (Slavin, 2002). There is evidence that the dissemination of the results 
of projects funded by federal R\&D agencies occurs through collegial contacts and information producers and intermediaries (Pinelli \& Barclay, 1998, p. 164). It is problematic to rely on these sources alone. Collegial contacts, for example, may have highly focused and limited knowledge about a topic since much education research is interdisciplinary. Furthermore, information producers and intermediaries transmit information from the source to the user, but do not respond to users' contexts; they retrofit user requirements into established modalities (Pinelli \& Barclay, 1998, p. 164).

- Gaps in existing information resources. Objective, easy-to-find, consumeroriented education information for making decisions on issues such as school readiness, school choice, or teacher selection, for example, is lacking. Former Secretary of Education Margaret Spellings has drawn attention to this (Feller, 2006).

- A multitude of resources with different search engines. Although the Internet has an extraordinary amount of information, it is organized in ways that make finding authoritative information difficult. It is time-consuming and difficult to identify information useful for education researchers and policy makers (Stacey, 2007). The existence of a government-subsidized database of peer-reviewed education literature (Weiner, 2009) along with several commercial databases with similar content is unnecessarily duplicative and confusing. Also, there are education researchers and policy makers whose primary discipline is not education. Their fields may include political science, sociology, and economics, for example. 
Each of those disciplines has its own body of literature accessible through specialized databases, further complicating the information search.

- Lack of a centralized body of education information experts to make decisions about and influence the development of needed education resources. This may help to explain the evolution of the role of the federal government in support of the collection, dissemination and delivery of education information.

- Scarce resources for the development and evaluation of various concepts, models, theories, techniques and methodologies related to the use of information and communication technologies for learning and teaching (Levy et al., 2003, p. 299). In fact, even in the field of information science, there is little understanding, much less consensus, on the future direction of discovery systems and the role of metadata in locating information. New systems with enhanced functionalities populate the discovery landscape. Some systems, such as Google, feature search results listed according to relevance ranking algorithms. Others offer faceted displays of results, allowing researchers to narrow their search at the click of a mouse. Systems such as del.icio.us and flickr use extensive visual displays to depict the relationship of concepts and terms.

- Minimal understanding of how people access and use education information as well as how people use digital information resources, services, systems, environments and communications media for learning and education (Levy et al., 2003, p. 299). Unfortunately, there is reason to believe that the research that has been done in this area is "fragmented and ambiguous" (Pinelli \& Barclay, 1998, p. 168). Students at all levels are developing information seeking behaviors in new 
ways, using new tools, ignoring traditional abstracting and indexing services and library catalogs. Text messages, social networks, blogs, wikis and commercial resources such as Amazon.com are now the norm. The emergence of free, open access, scholarly materials on the Internet offers further justification for the study of education information seeking behavior.

- Support for international and cross-cultural collaborations in education informatics (Stacey, 2007). Information technology enables scholarly communication world-wide, yet, as can be seen in the proliferation of independent systems and services, there are no universally accepted standards for the storage and retrieval of textually based information, much less for visual materials, geospatial data, numeric data sets, digitized sound recordings, etc. Furthermore, the need to address cross-cultural inequities in access to information is imperative. For all of these reasons the creation of a sub-discipline within the field of education which examines issues falling at the intersection of education information and information technology is critical. Once there is a broader recognition of the existence of this sub-discipline, it is likely that research funding will increase, specialized expertise will be expanded, and new programs and systems related to education information developed.

\section{Definitions of Informatics}

The origins of informatics can be traced to the mid-twentieth century (Collen, 1994, p. 91). It emerged in medicine but has been adopted by other disciplines, including: nursing, public health, bioinformatics, (Wan, 2006, p. 335), environmental informatics (Avouris \& Page, 1995), behavioral health (Dewan, Lorenzi, Riley, \& 
Bhattacharya, 2001), organizations (Beynon-Davies, 2002), community informatics (Marshall, Taylor, \& Yu, 2003), social work (Parker-Oliver \& Demiris, 2006), and social informatics (Kling, Rosenbaum, \& Sawyer, 2005). Definitions of informatics commonly incorporate the crossing of disciplines. "Informatics is an interdisciplinary science employing information on science, information technology and statistics” (Wan, 2006, p. 333). A program at the University of Indiana claims that informatics develops new uses for information technology to solve specific problems in diverse areas ("What is informatics?") When applied to nursing, informatics "integrates nursing science, computer science, and information science to manage and communicate data, information, and knowledge in nursing practice" (Scope and Standards of Nursing Informatics Practice, 2001, p. vii).

Other aspects of informatics include: "understanding and promoting the effective organization, analysis, management, and use of information” ("About informatics," 2007); “a reliance on knowledge-based or evidence-based decision-making” (Wan, 2006, p. 333); and "the integration of data, information and knowledge" (Scope and Standards of Nursing Informatics Practice, 2001, p. vii).

There have already been calls for the establishment of a discipline of education informatics (Stewart, 2000, p. 5) which would consolidate informatics efforts in education into a field of study that would include information science (Stewart, 2000, pp. 3-4). The definition of education informatics cited by Stewart is narrow, however: "the collection, classification, storage, retrieval, and dissemination of recorded knowledge treated both as a pure and as an applied science” (Stewart, 2000, p. 4). This definition centers on the "recorded knowledge" whereas our definition centers on users of that 
knowledge and the information problems they experience. By focusing on the user, information problems can readily be identified. This will result in practical solutions and, therefore, provide incentives for the adoption of the solutions.

Other existing definitions that encompass a larger scope that seems more relevant to education information needs are: the "study of the development and application of digital technologies in relation to the analysis, storage, manipulation, retrieval and use of information selected from multiple independent information sources, in relation to learning” (Ford, 2004, p. 183); and “the study of the application of digital technologies and techniques to the use and communication of information in learning and education” (Levy et al., 2003). Levy, et al, view education informatics as the crossroads between information science, education, and computer science (Levy et al., 2003, p. 299). Like the definition cited in the previous paragraph, these definitions center on the technologies used rather than on the users and their information problems. Levy's view of education informatics as the crossroads of three disciplines is limiting, too, in that there are additional disciplines that might be included in the list, such as anthropology and psychology. The established disciplines, themselves, are experiencing much intermingling. Limiting education informatics to the crossover of three areas could inhibit future investigations that might incorporate insights from unexpected disciplines.

\section{Existing Foundations for Education Informatics}

The U.S. Department of Education has long been concerned with the application of technology to the discovery and communication of education information. The Education Resources Information Center (ERIC) is a prime example. Established in the 1960s, ERIC was among the first online bibliographic databases, providing access to a 
wealth of published and unpublished education-related materials. ERIC was designed to address an education problem using technology of the time. The problem was identifying and providing access to education information. The solution was subject-specific clearinghouses located throughout the United States. Their purpose was to identify and collect relevant materials, create metadata and indices, and enter the records into the ERIC database. This system has existed for over forty years, and in many ways, continues to serve as a model discipline-related information resource (Weiner, 2009).

The federal role in the provision of education information services has been extensive. In fact, a 1985 reorganization of the Office of Educational Research and Improvement created the Information Services Program, whose mission it was to "promote aggressively the expansion of knowledge about education on the part of policymakers, practitioners, parents and the public through services, systems and products that transmit information about the condition and status of American education.” (Collins, 1988, p. 2). Within the Information Services Program, a division entitled Education Information Resources housed ERIC, the Education Research Library, the Education Reference Center, Information Technology Branch and a Technology Resource Center (Collins, 1988). Throughout the 1990s a variety of enhancements, changes in delivery mechanisms and new programs and services emerged in uncoordinated ways within the DOE, as the education community struggled to keep pace with rapid advances in information technology and the proliferation of education information. In 1997, the National Library of Education was founded to be a counterpart to the National Libraries of Medicine and Agriculture and the Library of Congress in supporting the access, management and delivery of education information (National 
Library of Education, Advisory Task Force, 1987). It was not funded at a level, however, that would allow it to provide the same depth of resources and services as those offered by these long-established institutions.

Expanding on the ERIC system, the National Education Network was established in 1998 to "promote seamless access to education information through quality services" (Lankes \& Sutton, 1999, p. 179). It was to be a policymaking organization and build bridges "between the aggregators and organizers of education information and tool builders and services” (Lankes \& Sutton, 1999, p. 179). It, too, along with a number of additional federal programs offering education information services, failed to reach its promise.

It is quite clear that the U.S. Department of Education has long recognized its role in supporting the creation, collection, organization, preservation and dissemination of education information. What has been lacking, however, is a widely recognized vision of education informatics. The education research community has not articulated the need for a discipline of this nature and the information science community has not focused enough attention on education. The result has been a series of disconnected efforts and individual attempts to address issues associated with the discovery and communication of education information.

\section{The Evolution of Academic Disciplines}

Academic disciplines are "institutionally established mechanisms for the production of legitimate kinds of knowledge within higher education” (Downing, 2005, p. 75). They are organized forms of knowledge production that use particular practices (Shumway \& Dionne, 2002, pp. 1-2). Disciplines are foundational to American 
universities and provide a professional identity for intellectuals (Abbott, 2002, p. 210). They have separate organizational structures within the academy and form: "a community, a network of communications, a tradition, a particular set of values and beliefs, a domain, a mode of enquiry, and a conceptual structure” (Becher, 1989, pp. 1920). The procedures that all disciplines have in common are: exploring, describing, explaining, reasoning, and inventing (Belth, 1969, p. 10).

According to Braxton and Hargens, "differences among academic disciplines are profound and extensive” (Braxton \& Hargens, 1996, p. 35). They vary in the level of consensus they have in relation to theory, methods, and means that they use to acculturate graduate students to their disciplines; course content and degree requirements; the functioning of scholarly journals; and research and teaching activities (Braxton \& Hargens, 1996, pp. 12-13, 16-17); (Belth, 1969, pp. 6-16).

Each discipline has a particular identity and culture (Becher, 1989, p. 22). Cultural identity refers to the "traditions, customs and practices, transmitted knowledge, beliefs, morals and rules of conduct, as well as their linguistic and symbolic forms of communication and the meanings that the members of a discipline share” (Becher, 1989, p. 24).

Academic disciplines commonly fragment into specialties. Sub-disciplines can result in new paradigms that establish new kinds of knowledge (Downing, 2005, p. 91). The core knowledge in disciplines tends to grow, while peripherally related knowledge does not (Becher, 1989, p. 41). The new knowledge that disciplines produce can destabilize the current body of knowledge. Paradigmatic research can result in unexpected results that can "threaten the boundaries that the paradigms seek to control" 
(Downing, 2005, p. 94). Paradigms are "normalizing mechanisms that, once institutionalized, can exclude other forms of knowledge and discourse that do not adhere to the paradigm” (Downing, 2005, p. 96). For some disciplines, such as many of the sciences, data analysis is paramount for creating new knowledge. In some of the social sciences and humanities, however, synthesizing information is key. One of the ways to categorize disciplines is to determine whether analysis or synthesis of information is predominant. The natural sciences and mathematics favor a process of reduction and atomization of problems (Becher, 1989, p. 14). This means that these disciplines attempt to solve problems by examining them from the most basic level to develop solutions. Convincing explanations develop in the hard pure disciplines "because they derive from the systematic scrutiny of relationships between a few carefully controlled variables” (Becher, 1989, p. 14). In the soft disciplines, such as the field of education, explanations tend to be weaker because there are usually more variables to consider. One view of the sciences is that they are impersonal and free of value judgments; whereas the humanities and social sciences are personal and value-laden (Becher, 1989, p. 14).

As disciplines evolve, new forms of knowledge can emerge (Becher, 1989, p. 16). Paradigmatic changes occur when it is not possible to reconcile discrepancies using the dominant paradigm. When solutions do not address the anomalies there is a need for a new paradigm. Solutions that resolve the anomaly form a new paradigm (Downing, 2005, p. 97).

Lines between academic departments and disciplinary fields are increasingly more difficult to identify (Schall, 2001, p. 69). Disciplines can continually renew and challenge each other because of this overlap (Abbott, 2002, p. 217). Interdisciplinarity 
can refer to "a subdisciplinary exchange, a multidisciplinary affiliation, an interdisciplinary solution, an integrative approach, a collaborative project, a transdisciplinary paradigm, or a cross-disciplinary critique” (Klein, 1996, p. 10). When a subdiscipline becomes too broad or blends with another subdiscipline, it may become a separate discipline (Becher, 1989, pp. 45, 140).

\section{Potential Synergies between Informatics, Library Science, and Education}

Information technology is key to knowledge diffusion, but understanding and developing human interaction, human behavior, and information use and exchange are also essential (Pinelli \& Barclay, 1998, p. 168). Just as educational psychologists and learning theorists studied the potential for television and other technologies leading to the development and delivery of educational programs and services, so too must they examine the application of information technology at all levels, from scholarly communication models developing within higher education, to the social networking systems and information seeking practices of school children, in order to inform the creation and use of education information systems.

The fields of library and information science have a role to play in the development of education informatics. Although libraries have been traditionally based on a model of provision of documents and information, libraries can become oriented around problem identification and responding with solutions (Pinelli \& Barclay, 1998, p. 168). For example, education librarians are in a position to study user behavior of a variety of groups engaged in the education information seeking process. They can be key to the development of new discovery systems, creating digital products, web sites, online 
help through tutorials and personal consultation, and collaborating with faculty to enhance course management systems.

\section{A Possible Future for Education Informatics}

For education informatics to become an established discipline, its characteristics and goals should be clearly defined (Belth, 1969, p. 4). This process could be advanced through an invited symposium on education informatics. Those who attend could begin to describe the character of the discipline in alignment with research in other academic disciplines. Leaders in education, library science, and related fields could specify goals for the discipline. Grounding it in schools of education would help to establish an academic identity. This would help in attracting students, which is essential for credibility and status (Belcher, 1989, p. 143).

Interdisciplinary fields need attention from a variety of funding agencies and research leadership; acceptance by faculty and students; and systemic implementation from university management (Rhoten, 2004, p. 6). "Interdisciplinary centers need not only to be well-funded but to have an independent physical location and intellectual direction apart from traditional university departments. They should have clear and wellarticulated organizing principles... around which researchers can be chosen on the basis of their specific technical, methodological, or topical contributions, and to which the researchers are deeply committed.” (Rhoten, 2004, page 6). The establishment of a "center" for education informatics would help to address problems that require many resources; incubate new programs; facilitate cross-disciplinary collaboration, attract outside funding and publicity, and provide an institutional foundation for new methods and approaches (Klein, 1996, p. 27). 
Informatics journals already exist for many of the specialized informatics subdisciplines: Advanced Engineering Informatics; CBI Journal: Chem-Bio Informatics Journal; Computing and Informatics; Intelligence and Security Informatics; Journal of the American Medical Informatics Association (JAMIA); Journal of Environmental Informatics; Management Informatics; Mathematics and Informatics Quarterly; Nursing Informatics Annual; and Usage-based Linguistics Informatics. In fact, the Lithuanian Academy of Sciences publishes Informatics in Education and the International Academy for Information Management publishes the Journal of Informatics Education and Research. However, both journals focus on educational technology. A journal of education informatics with a broader scope than educational technology would "promote communication among individuals who are dispersed across disciplinary and professional sites...[and] provide outlets for work that may not find a ready niche in traditional disciplines” (Klein, 1996, p. 27). It would lend credibility to the discipline.

An important aspect of education informatics is the management and dissemination of existing knowledge. A proposal for a knowledge management system that can be applied to education requires a shared vision, effective leadership and a collaborative approach, along with the following:

- Development of a plan with objectives and needs for managing educational knowledge.

- Information audit of what knowledge currently exists and what may be needed.

- Assignment of responsibility for knowledge management activities.

- Development of policies and methods that include evaluation criteria. 
- Creation of a repository of information that promotes collaboration, sharing, and diffusion of information (Pinelli \& Barclay, 1998, p. 165).

To illustrate the depth and breadth that education informatics could take, consider the following research topics already suggested in the literature by Levy (Levy et al., 2003, pp. 299, 302):

- The development and evaluation of concepts, models, theories, techniques and methodologies related to the use of Information and Computing Technologies (ICT) for learning and teaching (Levy et al., 2003, p. 299).

- Ways in which people use digital information resources, services, systems, environments and communications media for learning and education. (Levy et al., 2003, p. 299).

- How "knowledge about appropriate pedagogies, ICT and IM (Information Management) strategies, management approaches and instructional materials, together with systems and environments” (Levy et al., 2003, p. 299) can contribute to the development of practice.

- Whether information literacy educators give adequate attention to teaching all aspects of information literacy (Levy et al., 2003, p. 302).

Other possible research areas are how international and cross-cultural collaborations in education informatics can be supported (Stacey, 2007); and what the nature of information is and whether it changes over time (Macgregor, 2005, p. 20). 


\section{CONCLUSION}

In conclusion, the time is right for the development of a sub-discipline of education informatics. It is a logical extension of the directions in which the disciplines of education, information technology, and library science have evolved. Numerous other disciplines have created informatics sub-disciplines with corresponding journals: which will be the first college or university to institutionalize it? 


\section{References}

Abbott, A. (2002). The disciplines and the future. In S. Brint (Ed.), The city of intellect: The changing American university (pp. 205-230). Stanford, CA: Stanford University Press.

About informatics. (2007). Retrieved Nov. 11, 2007, from http://www.amia.org/informatics/

Avouris, N. M., \& Page, B. (Eds.). (1995). Environmental informatics: Methodology and applications of environmental information processing. Boston, MA: Kluwer Academic Publishers.

Becher, T. (1989). Academic Tribes and Territories: Intellectual enquiry and the cultures of disciplines. Bristol, PA: Society for Research into Higher Education \& Open University Press.

Belcher, T. (1989). Academic tribes and territories: Intellectual enquiry and the cultures of disciplines. Bristol, PA: Society for Research into Higher Education \& Open University Press.

Belth, M. (1969). Education as a Discipline: A study of the role of models in thinking. Boston, MA: Allyn and Bacon.

Beynon-Davies, P. (2002). Information systems: An introduction to informatics in organisations: Palgrave.

Braxton, J. M., \& Hargens, L. L. (1996). Variation among academic disciplines: Analytical frameworks and research. Higher Education: Handbook of Theory and Research, XI, 1-46. 
Collen, M. F. (1994). The origins of informatics. Journal of the American Informatics Association, 1(2), 91-107.

Collins, J. W. (1988). A comprehensive education information service center: Rationale and structure. Commissioned paper, U.S. Department of Education.

Dewan, N. A., Lorenzi, N. M., Riley, R. T., \& Bhattacharya, S. R. (Eds.). (2001). Behavioral healthcare informatics. New York: Springer-Verlag.

Downing, D. B. (2005). The knowledge contract: Politics and paradigms in the academic workplace. Lincoln, Nebraska: University of Nebraska Press.

Feller, B. (2006, Sept. 26). Spellings offers to ease college process. Washington Post.

Ford, N. (2004). Towards a model of learning for educational informatics. Journal of Documentation, 60(2), 183-225.

Klein, J. T. (1996). Crossing Boundaries: Knowledge, Disciplinarities, and Interdisciplinarities. Charlottesville and London: University Press of Virginia.

Kling, R., Rosenbaum, H., \& Sawyer, S. (2005). Understanding and communicating social informatics: A framework for studying and teaching the human contexts of informaton and communication technologies. Medford, NJ: Information Today.

Lankes, R. D., \& Sutton, S. A. (1999). Developing a mission for the National Education Network: The challenge of seamless access. Government Information Quarterly, 16(2), 169-181.

Levy, P., Ford, N., Foster, J., Madden, A., Miller, D., Nunes, M. B., et al. (2003). Educational informatics: An emerging research agenda. Journal of Information Science, 29(4), 298-210. 
Macgregor, G. (2005). The nature of information in the twenty-first century:

Conundrums for the informatics community? Library Review, 54(1/2), 10-23.

Marshall, S., Taylor, W., \& Yu, X. (Eds.). (2003). Using community informatics to transform regions. Hershey, PA: Idea Group.

Parker-Oliver, D., \& Demiris, G. (2006). Social work informatics: A new specialty. Social Work, 51(2), 127-134.

Pinelli, T. E., \& Barclay, R. O. (1998). Maximizing the results of federally-funded research and devlopment through knowledge management: A strategic imperative for improving U.S. competitiveness. Government Information Quarterly, 15(2), 157-172.

Rhoten, D. (2004). Interdisciplinary research: Trend or transition. Items \& Issues (Social Science Research Council), 5(1-2), 6-11.

Schall, J. V. (2001). On the academic discipline of "political science". Perspectives on Political Science, 30(2), 69-72.

Scope and Standards of Nursing Informatics Practice. (2001). Silver Spring, MD: American Nurses Association.

Shumway, D. R., \& Dionne, C. (Eds.). (2002). Disciplining English: Alternative histories, critical perspectives. Albany: State University of New York Press.

Slavin, R. E. (2002). Evidence-based education policies: Transforming educational practice and research. Educational Researcher, 31(7), 15-21.

Stacey, P. (2007). Open educational resources in a global context. First Monday, 12(4). 
Stewart, R. G. (2000). Informatics as a field of study in education: A needs assessment and research agenda. Paper presented at the Annual Meeting of the Mid-South Educational Research Association.

Trester, D. J. (1981). ERIC: The first fifteen years. Bethesda, MD: ERIC Processing and Reference Facility.

Wan, T. T. H. (2006). Introduction. International Journal of Public Policy, 1(4), 333342.

Weiner, S. A. (2009). Tale of two databases: The history of federally funded information systems for education and medicine. Government Information Quarterly, 26(3), 450-458.

What is informatics? (Jan. 24, 2006). Retrieved Nov. 11, 2007, from http://www.informatics.indiana.edu/overview/what_is_informatics.asp 